\title{
RHE ROLE OF THE LEADER IN EMPOWERING AND SUPPORTING EMPLOYEES TOWARDS SUSTAINABLE DEVELOPMENT
}

\author{
Danijela Vujić \\ University of Defence in Belgrade, Military Medical Academy \\ Srđan Novaković \\ Mlađan Maksimović \\ Darjan Karabašević \\ University Business Academy in Novi Sad, \\ Faculty of Applied Management, Economics and Finance, Belgrade
}

\begin{abstract}
The modern world is moving from an industrial society towards a knowledge-based economy. In such a society, there is a need for inventive leaders, i.e. the leaders who will become the key comparative advantage of modern organizations. Therefore, in today's business conditions, more attention is paid to leadership. As a specialized management discipline, leadership is becoming the inevitable factor that has an impact on the business performance of organizations. Leadership can be seen as a process in which an individual influences the other members of the group in order to achieve common goals. Leadership should not be focused on one single position or one single individual, but on certain characteristics that have to be developed by all the members of the organization. Bearing in mind the fact that sustainable development is an important issue for mankind, as well as for organizations, the paper is aimed at determining the role that a leader has in empowering and supporting employees towards sustainable development.
\end{abstract}

Key Words: leaders, leadership, empowering, sustainable development

\section{Introduction}

Modern organizations pose major challenges to leaders. Based on growing demands, the manager of the $21^{\text {st }}$ century will have to possess four basic characteristics, namely to be a global strategist, the master of technology, a "par excellence" politician, and a leader - a motivator (Vujić, 1999).

Leadership is an important determinant of organizational development. Hogan et al. (1994) states that the role of leadership is to motivate and inspire others in order to create positive attitudes at work while creating a sense of contribution and significance

1srdjan.novakovic@mef.edu.rs 
among employees. According to Stefanović and Stefanović (2007), leadership is a manager's function that includes the process of communication, influence, belief, group management and motivation of others for the purpose of successfully accomplishing their tasks and achieving organizational goals. Northouse (2010) says that leadership is a process by which an individual influences a group in order to achieve common goals. He also states that management and leadership are different overlapping concepts. The difference between them is that management traditionally focuses on planning, organizing and controlling activities, whereas leadership emphasizes the overall impact of the process. Milisavljević (2005) states that leadership is the key component that will enable organizations to achieve a competitive advantage in the future because leadership generates intellectual capital. However, leadership is defined as an act or behavior that affects others. Therefore, leadership is the process that involves influencing the achievement of goals and it occurs in a particular situation of a group or organization. Gardner (1993) sees leadership as the persuasion process by which an individual (or a leadership team) encourages a group to pursue the goals set by the leaders.

There is the authors' general agreement that the essence of leadership reflects in its ability to create or articulate a vision and influence followers to work towards the realization of the vision, which creates changes. In general, leadership is the process of achieving an impact in terms of the ability to convince the leader of other people, i.e. followers, to follow him/her on the path to achieving organizational goals. The art of managing through the complexity of leadership implies the involvement of followers and leaders in the process of achieving goals, but without coercion, i.e. through freely chosen participation.

The leader is someone who is ready to bear the burden of reality and present that reality to others in the organization. The ability of the leader is to understand the reality in which the organization is, analyze and process information from the environment, which is exactly what makes him/her superior to others. He/she should use that power by transferring his/her knowledge to other employees by directing their mental and physical abilities towards the right path, i.e. by directing their energy so that the organization has the biggest benefit.

The last two decades of the twentieth century represented a milestone for the adoption of the provision of sustainable development as the key ethical and political paradigm in order to solve the environmental and social problems that affected the planet Earth. The first "inauguration" of the concept of sustainable development on a global scale was held in 1987 by the World Commission on Environment and Development (Brundtland Commission), but its etymology is much older. Development is now not understood in the same way as it was in 1972 or 1987 . After the multi-year evolution, it represents freedom, the expansion of the perspective and the option of choice, and it puts man in the center of the future (Gond et al., 2012; Marković Blagojević et al., 2018).

The most commonly used definition of "sustainable development" is that proposed by Lester Brown, the founder of the Worldwatch Institute. It is also listed in the "Our Common Future" report of the Brundtland Commission: "Sustainable development is development that meets the needs of the present without compromising the ability of future generations to meet their own needs" (Veljković, 2012; WCED, 1987; Maksimović et al., 2018). Hence, sustainable development represents the harmonization of the three key dimensions, namely the ecological, social and economic one.

Sustainable development is an important issue for humankind, and it involves providing all citizens with the opportunity to acquire knowledge, skills, habits, values and raise 
awareness, so as to participate in the decision-making that will improve their quality of life, while simultaneously not endangering future generations in meeting their needs. The concept of sustainable development is an alternative to the search for "unrestrained development". Conventional approaches saw development in the context of the modernization process, which society assumed to be technically and technologically sophisticated, urbanized, with a developed market economy (Marković Blagojević et al., 2018).

Lately, the link between leadership, sustainable leadership and sustainable development as the important elements for creating a sustainable organization has increasingly been mentioned. Accordingly, Hargreaves and Fink (2003) make the following statement on the concept of sustainable leadership: "Sustainable leadership matters, spreads and lasts. It is a shared responsibility that does not unduly deplete human or financial resources, and that cares for and avoids exerting damage on the surrounding educational and community environment". Also, they point out the seven principles of sustainable leadership: 1) Depth; 2) Endurance; 3) Breadth; 4) Justice; 5) Diversity; 6) Resourcefulness, and 7) Conservation. In his research, Baumgartner (2009) also confirms the impact of organizational culture and leadership on the creation of a sustainable organization, and points out the fact that organizations have great importance in creating sustainable communities. The level of the implementation of the concept of sustainable development primarily depends on leaders in an organization and organizational culture.

In today's business conditions, leadership is becoming an indispensable factor that the development of an organization is based on. Leaders are those who create an atmosphere in the organization in which employees will be able to learn and develop, while fostering and creating an organizational culture that respects the concept of sustainable development at the same time, i.e. the ecological, economic and social dimensions of sustainable development as a concept that the development of organizations is based on. Based on the abovementioned, the aim of the paper is to examine the role of leaders in empowering and supporting employees in the direction of implementing the concept of sustainable development in an organization.

\section{Materials and Methods}

Research on the role of leaders in empowering and providing support to employees in the direction of sustainable development was conducted in the period from March $15^{\text {th }}$, 2017 to June $30^{\text {th }}, 2017$. The study included four enterprises in Belgrade. A survey questionnaire was used as a research instrument. The research was anonymous, while a total of 300 questionnaires were distributed. There are 260 validly filled out questionnaires relevant to the research, which represents $86.66 \%$ of the respondents. The response level and the validly filled-out questionnaires are expected, and they correspond to the results recommended in the literature (Das et al., 2000; Kayank, 2003).

In addition to the basic demographic characteristics, such as gender, age, and education, the respondents rated the following statements on the five-step Likert scale with the grades ranging from 1 (strongly disagree) to 5 (strongly agree). The research started from the following findings that were the subject matter of evaluation by the respondents:

- The leader in my organization represents a significant link for the successful and sustainable development of companies.

- The leader in my organization makes the maximum contribution to the organization's sustainable operation. 
- Guided by personal moral standards, the leader in my organization positively influences the behavior of the employees.

- The leader in my organization provides support and encourages the employees to present opposing opinions and views.

- The organization's employees are more committed to their work due to the empowerment and support received from the leaders.

- Through the management methods, the leader does not only address economic issues, but environmental issues, as well.

- In his/her day-to-day business activities, in addition to economic benefits, the leader also puts an emphasis on the preservation of natural resources.

- In his/her everyday work, the leader in my organization places the maximum emphasis on business in accordance with the concept of sustainable development.

- The leader plays an important role in creating an organization of high business performance.

- The leader in my organization always has a convincing vision and his/her actions are always focused on the organization's interests.

\section{Research Results and Discussion}

Out of the respondents who participated in the study, out of the total number of the respondents from all the four enterprises, $47.86 \%$ are male and $52.14 \%$ are female. Out of the total number of the respondents from all the four enterprises, there were $10.71 \%$ of the respondents of 18 to 24 years of age; $15.71 \%$ of the respondents of 25 to 30 years of age; $32.86 \%$ of the respondents of 31 to 45 years of age; $27.86 \%$ of the respondents of 46 to 60 years of age, and $12.86 \%$ of the respondents of 60 years of age and over. Out of the total number of the respondents, there were $61.43 \%$ of the respondents with secondary education; $35 \%$ of the respondents with college education and $3.57 \%$ of the respondents with a university degree. According to the status of employment in the organization for all the four enterprises, there were $99.29 \%$ employees and $0.71 \%$ managers-leaders.

Table 1 - The leader's focus on empowering and providing support to employees

\begin{tabular}{|c|c|c|c|c|c|}
\hline & 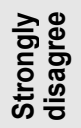 & 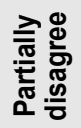 & 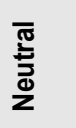 & 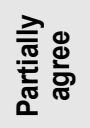 & 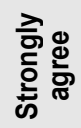 \\
\hline $\begin{array}{l}\text { The leader in my organization represents a sig- } \\
\text { nificant link for the successful and sustainable de- } \\
\text { velopment of companies. }\end{array}$ & $0.0 \%$ & $0.0 \%$ & $7.9 \%$ & $64.3 \%$ & $27.9 \%$ \\
\hline $\begin{array}{l}\text { The leader in my organization makes the maxi- } \\
\text { mum contribution to the organization's sustainable } \\
\text { operation. }\end{array}$ & $0.0 \%$ & $0.0 \%$ & $6.4 \%$ & $61.4 \%$ & $32.1 \%$ \\
\hline $\begin{array}{l}\text { Guided by personal moral standards, the leader in } \\
\text { my organization positively influences the behavior } \\
\text { of the employees. }\end{array}$ & $0.0 \%$ & $0.0 \%$ & $7.1 \%$ & $40.7 \%$ & $52.1 \%$ \\
\hline
\end{tabular}


The Role of the Leader in Empowering and Supporting Employees towards Sustainable Development

\begin{tabular}{|l|l|l|l|l|l|}
\hline $\begin{array}{l}\text { The leader in my organization provides support } \\
\text { and encourages the employees to present oppos- } \\
\text { ing opinions and views. }\end{array}$ & $0.0 \%$ & $0.7 \%$ & $8.6 \%$ & $45.0 \%$ & $45.7 \%$ \\
\hline $\begin{array}{l}\text { The organization's employees are more commit- } \\
\text { ted to their work due to the empowerment and } \\
\text { support received from the leaders. }\end{array}$ & $0.0 \%$ & $0.0 \%$ & $6.4 \%$ & $56.4 \%$ & $37.1 \%$ \\
\hline $\begin{array}{l}\text { Through his/her management methods, the leader } \\
\text { does not only address economic issues, but envi- } \\
\text { ronmental issues, as well. }\end{array}$ & $0.0 \%$ & $0.0 \%$ & $6.4 \%$ & $52.1 \%$ & $41.4 \%$ \\
\hline $\begin{array}{l}\text { In his/her day-to-day business activities, in addi- } \\
\text { tion to economic benefits, the leader also puts an } \\
\text { emphasis on the preservation of natural re- } \\
\text { sources. }\end{array}$ & $0.0 \%$ & $0.0 \%$ & $13.6 \%$ & $52.1 \%$ & $34.3 \%$ \\
\hline $\begin{array}{l}\text { In his/her everyday work, the leader in my organi- } \\
\text { zation places the maximum emphasis on business } \\
\text { in accordance with the concept of sustainable de- } \\
\text { velopment. }\end{array}$ & $0.0 \%$ & $0.0 \%$ & $9.3 \%$ & $59.3 \%$ & $31.4 \%$ \\
\hline $\begin{array}{l}\text { The leader plays an important role in creating an } \\
\text { organization of high business performance. }\end{array}$ & $0.0 \%$ & $0.7 \%$ & $5.7 \%$ & $41.4 \%$ & $52.1 \%$ \\
\hline $\begin{array}{l}\text { The leader in my organization always has a con- } \\
\text { vincing vision and his/her actions are always fo- } \\
\text { cused on the organization's interests. }\end{array}$ & $0.0 \%$ & $0.0 \%$ & $5.0 \%$ & $47.1 \%$ & $47.9 \%$ \\
\hline
\end{tabular}

Table 1 shows that when the leader's focus on the empowerment of and providing support to employees is concerned, the respondents opine that the leader in the organization represents a significant link for the successful and sustainable development of companies, which the majority, i.e. over $90 \%$ of the respondents agree upon. Concerning the fact that the leader of the organization makes the maximum contribution to the organization's sustainable operation, almost $95 \%$ of the respondents agree upon that statement. As far as the statement that guided by personal moral standards the leader in the organization positively influences the behavior of its employees is concerned, it is also agreed on by $90 \%$ of the respondents. Regarding the statement that leader in the organization provides support to and encourages its employees to present their opposing opinions and views, almost $90 \%$ of the respondents agree on that statement. With respect to the statement that the organization's employees are more committed to their work due to the empowerment and support received from their leaders, almost $95 \%$ of the respondents agree upon that statement. Regarding the statement that through his/her management methods the leader does not only address economic issues, but environmental issues as well, almost $95 \%$ of the respondents agree upon that statement. In the case of the statement that in addition to economic benefits the leader also puts an emphasis in his/her day-to-day business activities on the preservation of natural resources, over $85 \%$ of the respondents agree upon that statement. When the statement that in his/her everyday work the leader in the organization places the maximum emphasis on business in accordance with the concept of sustainable development is concerned, over $90 \%$ of the respondents agree upon that statement. With respect to the statement that the leader plays an important role in creating an organization of high business performance, almost $95 \%$ of the respondents agree upon that statement. Finally, regarding the statement that the leader in the organization always has a convincing vision and that his/her actions are always focused on the interests of the organization, $95 \%$ of the respondents, too, agree upon that statement. 
Bearing in mind the fact that the obtained data was statistically different from the normal probability distribution regardless of the ranges from 3 to 5 , no conditions for parametric statistical tests were met. For this reason, the data was processed by doing a non-parametric statistical test.

Table 2 - The descriptive statistical parameters of the derived variables that explain the empowerment of and providing support to the employees and the employees' commitment to the successful sustainable development of companies

\begin{tabular}{|l|r|r|r|r|}
\hline & Average score & Standard deviation & Minimum & Maximum \\
\hline Employee support & 4.33 & 0.359 & 3.00 & 5.00 \\
\hline Employees' commitment & 4.17 & 0.415 & 3.00 & 5.00 \\
\hline
\end{tabular}

As can also be seen from Table 2, the compression of the variables resulted in the new determinants related to the employee support provided by the leader and the employees' commitment to the successful sustainable development of the companies surveyed in the observed economic entities in order to facilitate the interpretation and draw real conclusions. The newly-created variable referred to as the "employee support" has an average grade of 4.33 , with a standard deviation of 0.359 ; whereas the other variable referred to as the "employees' commitment" has an average grade of 4.17 , with a standard deviation of 0.415 . In order to determine whether there is a causal link between the "employee support" and the "employees' commitment" in the organization, the assessment of the given variables was evaluated, so as to determine whether they met the regularity of the normal distribution and whether some parametric statistical tests, to which the standard KolmogorovSmirnov test for normality was applied, were possible to apply.

Table 3 - The evaluation of the normality of the distribution of the derived parameters that explain the empowerment of and providing support to the employees and the employees' commitment to the successful sustainable development of the companies

\begin{tabular}{|c|c|c|c|}
\hline & \multicolumn{3}{|c|}{ Kolmogorov-Smirnov Test for Normality } \\
\hline & Statistics & $\mathrm{df}$ & Error probability \\
\hline Employee support & 0.178 & 260 & 0 \\
\hline Employees' commitment & 0.161 & 260 & 0 \\
\hline
\end{tabular}

Table 3 allows us to see that employee support and the employees' dedication significantly differ from the normal likelihood regardless of the ranges from 3 to 5 , so the conditions for parametric tests are not met, thus the data will be processed by doing a non-parametric statistical test. 
The Role of the Leader in Empowering and Supporting Employees towards Sustainable Development

Table 4 - The non-parametric statistical test for the assessment of the dependence between the empowerment of and providing support to the employees and the employees' commitment to the successful sustainable development of the companies

\begin{tabular}{|c|c|c|c|c|}
\hline & & & $\begin{array}{c}\text { Employee } \\
\text { support }\end{array}$ & $\begin{array}{l}\text { Employees' } \\
\text { commitment }\end{array}$ \\
\hline \multirow{6}{*}{ Kendall's tau_b } & \multirow{3}{*}{ Employee support } & Correlation coefficient & 1.000 & 0.411 \\
\hline & & Error probability & & 0.000 \\
\hline & & Number of respondents & 260 & 260 \\
\hline & \multirow{3}{*}{ Employees' commitment } & Correlation coefficient & 0.411 & 1.000 \\
\hline & & Error probability & 0.000 & \\
\hline & & Number of respondents & 260 & 260 \\
\hline \multirow{6}{*}{ Spearman's rho } & \multirow{3}{*}{ Employee support } & Correlation coefficient & 1.000 & 0.502 \\
\hline & & Error probability & & 0.000 \\
\hline & & Number of respondents & 260 & 260 \\
\hline & \multirow{3}{*}{ Employees' commitment } & Correlation coefficient & 0.502 & 1.000 \\
\hline & & Error probability of error & 0.000 & \\
\hline & & Number of respondents & 260 & 260 \\
\hline
\end{tabular}

Due to the accuracy and precision of the data because of a smaller sample, Kendall's tau_b test was applied due to a smaller number of the respondents, and Spearman's rho test was applied, where the data showed significant heterogeneity.

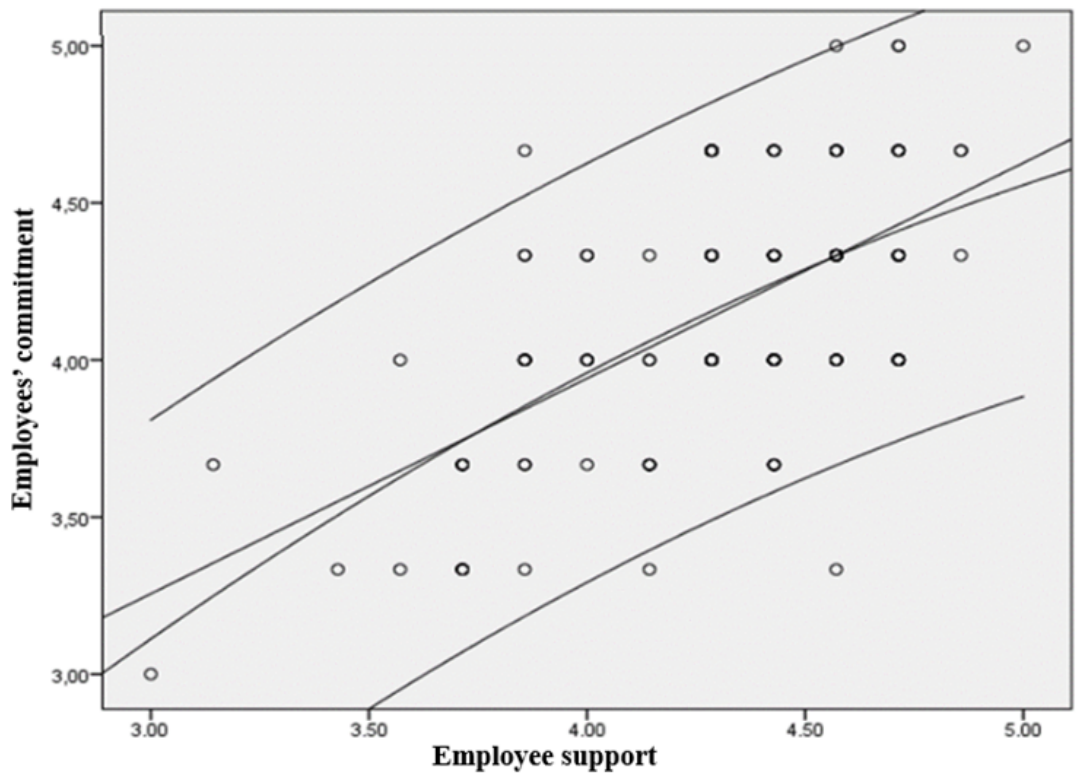

Figure 1 - The point diagram of the dispersal of the data between the empowerment of the employees, providing support to the employees and the employees' commitment to the successful and sustainable development of the companies 
Based on the data demonstrated in Table 4, it can be concluded that both tests gave almost identical results, which confirms precision in assessing the cause-effect relationships between the empowerment of and providing support to the employees and the employees' commitment to the successful sustainable development of the companies. This can also be seen in Figure 1, showing that as the growth of the ratings of one variable increases, the positive trend of the other variable increases, as well. Based on Henry's positive inclination in the chart, it is concluded that there is a very strong and positive and statistically significant relationship between the empowerment of and providing support to the employees and the employees' commitment to the successful and sustainable development of the companies.

\section{Conclusion}

Leadership can be seen as a process in which an individual influences the other members of the group in order to achieve common goals. Leadership should not be focused on one single position or one single individual, either, but leadership should rather be connected with certain characteristics that have to be developed by all the members of the organization.

Leaders have such charisma that they can initiate activities, inspire a vision, allow others to act, create the way that an organization should go and encourage everyone to follow. It is common for all leaders to set programs and goals, require work, discipline, have the ability to persuade, emphasize the importance of interpersonal relationships, and expect a reward for their hard work.

The leader's focus on the empowerment of and providing support to employees is reflected in the fact that the leader in the organization represents a significant link for the successful and sustainable development of companies because he/she makes the maximum contribution to the sustainable business of the organization. Guided by personal moral standards, the leader in the organization positively influences employees' behavior where he/she provides support to and encourages employees to express conflicting opinions and viewpoints. Being committed to their work due to the support and empowerment received from their leaders, employees do their best, which also makes it easier for the leader to focus not only on the economy, but also on environmental issues. In his/her day-to-day operations, in addition to economic benefits, the leader also puts an emphasis on the preservation of natural resources, placing the maximum emphasis on business in line with the concept of sustainable development. Through his/her work, the leader assumes an important role in creating an organization of high business performance because he/she always has a convincing vision and his/her actions are always oriented towards the interests of the organization. The research has shown that there is a very strong and positive statistically significant relationship between the empowerment of and providing support to employees and employees' commitment to the successful and sustainable development of companies.

\section{References}

[1] Baumgartner, R. J. (2009). Organizational culture and leadership: Preconditions for the development of a sustainable corporation. Sustainable development, 17(2), 102-113.

[2] Das, A., Handfield, R.B., Calantone, R.J., \& Ghoch, S. (2000). A contigent view of quality management: The impact of international competition on quality. Decision Sciences, 31, 649-690. 
[3] Gardner, J. W. (1993). On Leadership. The Free Press, New York.

[4] Gond, J. P., Grubnic, S., Herzig, C., \& Moon, J. (2012). Configuring management control systems: Theorizing the integration of strategy and sustainability. Management Accounting Research, 23(3), 205-223.

[5] Hargreaves, A., \& Fink, D. (2003). Sustaining leadership. Phi delta kappan, 84(9), 693-700.

[6] Hogan, R., Curphy, G., \& Hogan, J. (1994). What we know about leadership effectiveness and personality'. American Psychologist, 49, 493-504.

[7] Kayank, H. (2003). The relationship between total quality management practices and their effects on firm performance. Journal of Operations Management, 21(4), 405-435.

[8] Maksimović, M., Brzaković, M., \& Ristić, N. (2018). Paradigmatski aspekti obrazovanja za održivi razvoj. Ecologica, 25 (89), 86-89.

[9] Marković Blagojević, M., Karabašević, D., \& Brzaković, M. (2018). E-učenje i primena MOOC u funkciji održivog razvoja. Ecologica, 25(91), 619-624.

[10] Milisavljević, M. (2005). Savremeni strategijski menadžment. Megatrend univerzitet primenjenih nauka, Beograd.

[11] Northouse, P.G. (2010). Leadership theory and practice. SAGE Publications inc., Thousand Oaks, California.

[12] Stefanović, N. \& Stefanović, Ž. (2007). Liderstvo i kvalitet. Kragujevac.

[13] Veljković, N. (2012). Održivi razvoj u Srbiji. Agencija za zaštitu životne sredine, Beograd

[14] Vujić, D. (1999). Motivacija za kvalitet. Centar za primenjenu psihologiju društva psihologa Srbije, Beograd.

[15] WCED. (1987). Our Common Future. Oxford University Press, Oxford. 